\title{
Intranodal and extranodal tumour growth in early metastasised non-small cell lung cancer: Problems in histological diagnosis
}

\author{
P H M H Theunissen, E C M Bollen, J Koudstaal, F B J M Thunnissen
}

\begin{abstract}
Aim-To question the observer reliability or agreement of reports on the intranodal and extranodal tumour growth patterns in early metastasised non-small cell lung cancer (NSCLC).

Methods-In a pilot study original histological sections of mediastinal lymph node metastases from NSCLC obtained by lymph node dissection $(n=82)$ or by mediastinoscopy $(n=62)$ were examined and classified independently by three pathologists as extranodal, intranodal, or indefinite. After clear criteria for these growth patterns had been defined sections were re-examined and recategorised one year later. Interobserver agreement was examined for both investigations.
\end{abstract}

Results-In the dissected lymph nodes the $\kappa$ value improved significantly from 0.52 (moderate agreement) at the first investigation to 0.78 (good agreement) at the second. In the mediastinoscopic lymph node biopsy specimens an increase in $\kappa$ value from 0.50 at the first to 0.67 at the second examination was found, although this improvement was not significant. In mediastinoscopic biopsy specimens a very high proportion of tissue samples showed indefinite tumour extension.

Conclusion-Good reproducibility of intranodal and extranodal growth patterns in the histological examination of mediastinal lymph node metastases can be achieved, provided that pathologists use strictly defined criteria. In mediastinoscopic biopsy specimens it is often impossible to differentiate between intranodal and extranodal tumour growth.

Department of Pathology, De Wever Hospital, P O Box 4446, NL-6401 CX, Heerlen, the Netherlands P H M H Theunissen J Koudstaal

Department of Surgery

E C M Bollen

Department of Pathology, University Hospital, Maastricht, the Netherlands F B J M Thunnissen Correspondence to: Dr P H M H Theunissen Accepted for publication 19 April 1994 ipsilateral, and intranodal (minimal N2 disease) are patients potential candidates for surgery. ${ }^{3}$ Five year survivals of $20 \%$ or more have been reported after complete surgical resection in patients with minimal N2 dis-

The benefit of surgical resection in the pres nosed preoperatively less than $10 \%$ of all patients with $\mathrm{N} 2$ disease treated surgically survive five years. ${ }^{2}$ Only if lymph node metastasis discovered at mediastinoscopy is solitary, ease. ${ }^{3}$ Patients with minimal N2 disease have also been accepted as a special group in the European Organisation on Research and Treatment of Cancer study (08861) receiving adjuvant treatment for completely resected lung cancer. In addition to gross metastases and multiple lymph node disease extranodal tumour growth is regarded as advanced and unresectable disease. ${ }^{48} \mathrm{~A}$ recent study showed five year survivals in patients with $\mathrm{N} 2$ disease of $34 \%$ for those with intranodal invasion, but only $11 \%$ for those with extranodal invasion $(p<0.01) .{ }^{9}$ Clinicians obviously assume that extranodal tumour growth is a clearcut histological feature and a counterpart of intranodal tumour extension. In a previous study ${ }^{7}$ it was even stated that, "it was easy to classify lymphatic metastases as intranodal and perinodal because of the pathologists' detailed and clear descriptions of the resected tissue". However, criteria for these growth patterns are very ill defined and the reproducibility of these histological assessments should be regarded as questionable. The aim of the present study was to investigate the reproducibility of the histological features of intranodal and extranodal tumour growth in N2 metastasised NSCLC. The possibility of defining clear criteria for these growth patterns was also studied to improve this reproducibility.

\section{Methods}

Original histological sections of all mediastinal lymph node metastases obtained by mediastinal lymph node dissection ( $n=82,42$ cases) or by mediastinoscopy ( $n=62,38$ cases) in patients with NSCLC operated on between 1986 and 1992 were available for review. ${ }^{10}$ In a pilot study the haematoxylin and eosin stained sections were classified independently by three pathologists as to tumour extension: intranodal, extranodal, or indefinite. Strict criteria for the different growth patterns were not used in this pilot study. The diagnoses of the three pathologists were compared and the agreement of the group was statistically evaluated by means of Cohen's $\kappa$ statistic. ${ }^{11} 12$ The interobserver agreement was analysed separately for the dissected lymph nodes on the one hand and for the mediastinoscopic biopsy specimens on the other.

Strict criteria for three different categories of tumour extension were proposed at a consensus meeting, based on the experiences in the pilot study: tumour extension was classified as extranodal when either tumour pene- 


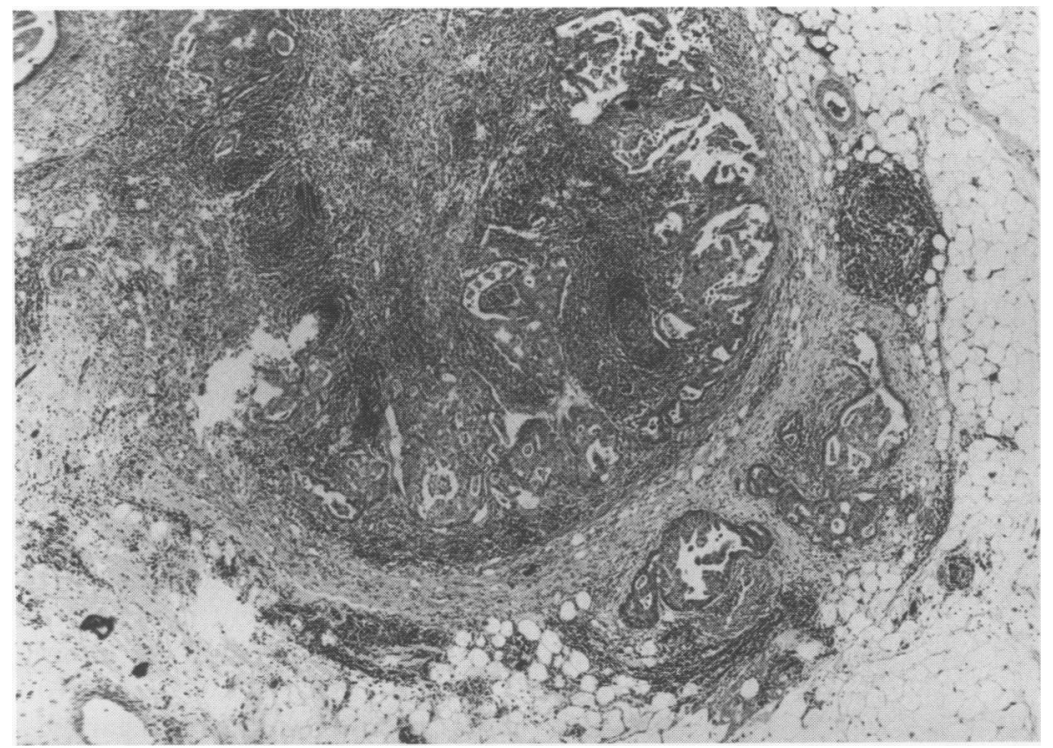

Figure 1 Mediastinal lymph node metastasis of a pulmonary adenocarcinoma with extranodal tumour extension: in this section there is unequivocal tumour penetration of the nodal capsule.
Table 3 Interobserver agreement on classification of tumour extension (intranodal, extranodal, or indefinite) in lymph node metastases obtained by mediastinoscopy $(n=62)$

\begin{tabular}{lll}
\hline & $\begin{array}{l}\text { First } \\
\text { examination }\end{array}$ & $\begin{array}{l}\text { Second } \\
\text { examination }\end{array}$ \\
\hline$\kappa$ observers $1+2$ & $0.53($ SE 0.11) & 0.71 (SE 0.09) \\
$\kappa$ observers 1 + 3 & $0.47($ SE 0.13) & $0.66($ SE 0.10) \\
$\kappa$ observers 2 + 3 & $0.51($ SE 0.11) & $0.64($ SE 0.10) \\
$\kappa$ all observers & $0.50($ SE 0.12)* & 0.67 (SE 0.10) $\dagger$ \\
\hline
\end{tabular}

95\% Confidence intervals $0 \cdot 26-0 \cdot 74^{\star}$ and $0 \cdot 47-0 \cdot 87 \dagger$.

\section{Results}

The frequency distribution of classified categories in the pilot study and in the second examination is shown in table 1 . On average, in $36 \%$ of dissected lymph node metastases the tumour extension was classified as indefinite in the pilot study. In mediastinoscopic biopsy specimens this percentage was $76 \%$. The overall interobserver agreement in the pilot study expressed as $\kappa$ was 0.52 for dissected lymph nodes (table 2) and 0.50 for mediastinoscopic biopsy specimens (table 3 ). In the dissected lymph nodes the overall interobserver agreement expressed as $\kappa$ was significantly better $(0.78)$ after using the newly defined criteria at the second examination (table 2). The frequency distribution of the classified categories showed a slight shift from indefinite to intranodal tumour extension, whereas the frequency of the category extranodal was not influenced by the use of the defined criteria (table 1). In mediastinoscopic lymph node biopsy specimens the interobserver agreement at the second examination improved ( $\kappa 0.67$ ), although this was not significant. The frequency distribution of the classified categories in mediastinoscopic biopsy specimens showed a slight shift from indefinite to extranodal tumour extension at the second examination.

Finally, after one year the sections of the lymph node metastases were re-evaluated independently by the pathologists for a second time, but now using the criteria defined in the consensus meeting. Interobserver agreement was again evaluated by means of Cohen's $\kappa$ statistic.

Table 1 Frequency distribution of classification categories in mediastinal lymph node metastases obtained by dissection (MND) or mediastinoscopy (MS)

\begin{tabular}{lllllr}
\hline & \multicolumn{2}{l}{$\begin{array}{l}\text { First } \\
\text { examination }\end{array}$} & & \multicolumn{2}{l}{$\begin{array}{l}\text { Second } \\
\text { examination }\end{array}$} \\
\cline { 2 - 3 } \cline { 5 - 6 } & $M N D$ & $M S$ & & $M N D$ & $M S$ \\
\hline Intranodal & $46 \%$ & $11 \%$ & & $59 \%$ & $8 \%$ \\
Extranodal & $17 \%$ & $13 \%$ & & $19 \%$ & $22 \%$ \\
Indefinite & $36 \%$ & $76 \%$ & & $22 \%$ & $70 \%$ \\
\hline
\end{tabular}

The percentages represent the mean of three observers.

Table 2 Interobserver agreement on classification of tumour extension (intranodal, extranodal, or indefinite) in lymph node metastases obtained by MND $(n=82)$

\begin{tabular}{lll}
\hline & $\begin{array}{l}\text { First } \\
\text { examination }\end{array}$ & $\begin{array}{l}\text { Second } \\
\text { examination }\end{array}$ \\
\hline$\kappa$ observers 1 + 2 & 0.66 (SE 0.07) & 0.85 (SE 0.06) \\
$\kappa$ observers 1 + 3 & 0.43 (SE 0.08) & 0.79 (SE 0.06) \\
$\kappa$ observers 2 + 3 & 0.47 (SE 0.08) & 0.70 (SE 0.07) \\
$\kappa$ all observers & 0.52 (SE 0.08)* & 0.78 (SE 0.06) $\dagger$ \\
\hline
\end{tabular}

$95 \%$ Confidence intervals $0.36-0.68^{\star}$ and $0.66-0.90+$.

\section{Discussion}

One of the purposes of the present study was to study the reproducibility (observer reliability or agreement) of the histological signs of intranodal and extranodal tumour growth. One possibility for measuring agreement between observers is to calculate the proportion of cases classified into the same category by all observers (observed agreement). Such a measure has the virtue of simplicity and is also readily understood. It is not, however, an adequate measure of agreement as it ignores agreement between observers that might be chance corrected measure of agreement was first suggested by Cohen (1960) and is known as the $\kappa$ coefficient. ${ }^{112} \kappa$ equals 0 if the observed proportion of agreement is only what could be expected by chance, and $\kappa$ equals 1 if the observers always agree completely. According to the guidelines of Landis and Koch, ${ }^{13}$ a $\kappa$ value of $<0.20$ can be interpreted as poor agreement, values of $0.21-0.40$ as fair, values of $0.41-0.60$ as moderate, values of $0 \cdot 61-0.80$ as good, and values of $0.81-1.00$ as excellent agreement. The $\kappa$ values in the present pilot study indicate that due to chance if they were guessing. The 


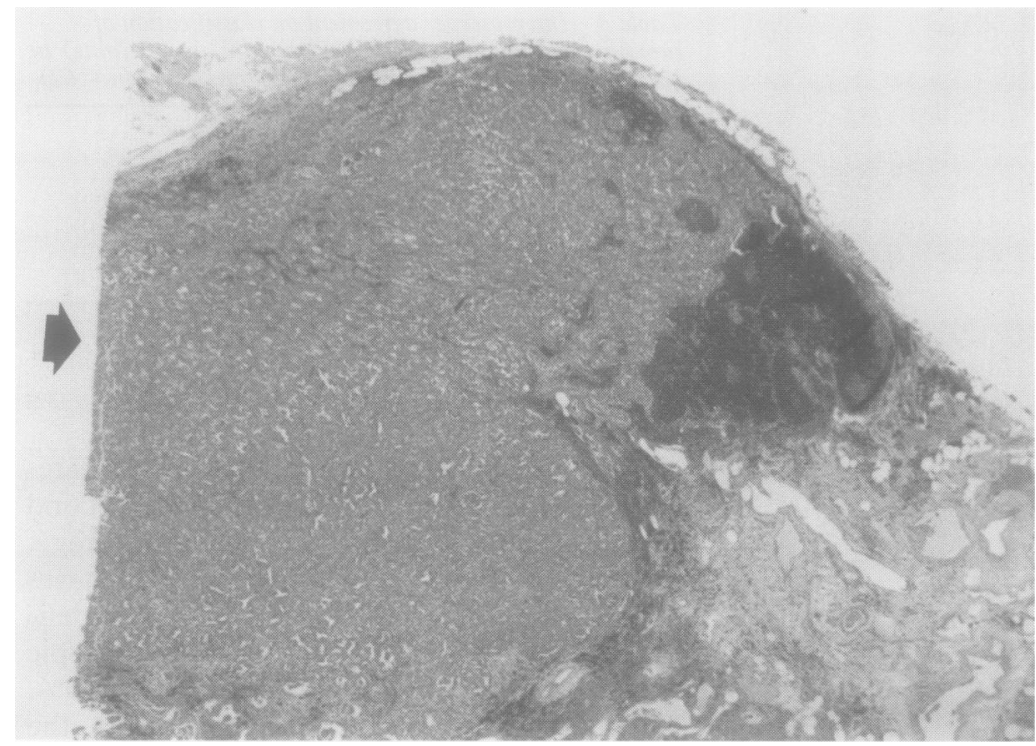

Figure 2 The incompleteness of this otherwise intranodal metastasis was caused by the pathologist: there is a straight cut edge on the left side (arrow).

considerable interobserver variation among pathologists can be expected when judging mediastinal lymph nodes for intranodal and extranodal tumour growth. Because of the important therapeutic consequences of these histological diagnoses it would be desirable for pathologists to use clearly defined criteria and thus reduce this interobserver variation to a minimum.

In the pilot study three quarters of mediastinoscopic metastatic biopsy specimens were classified as showing indefinite tumour extension. Tissue samples obtained by mediastinoscopy often contained only fragments of lymph nodes or tumour tissue making a definite distinction between intranodal and extranodal tumour growth very difficult if not impossible. To minimise the category of indefinite tumour extension the surgeon should try to remove lymph nodes completely when performing a mediastinoscopy.

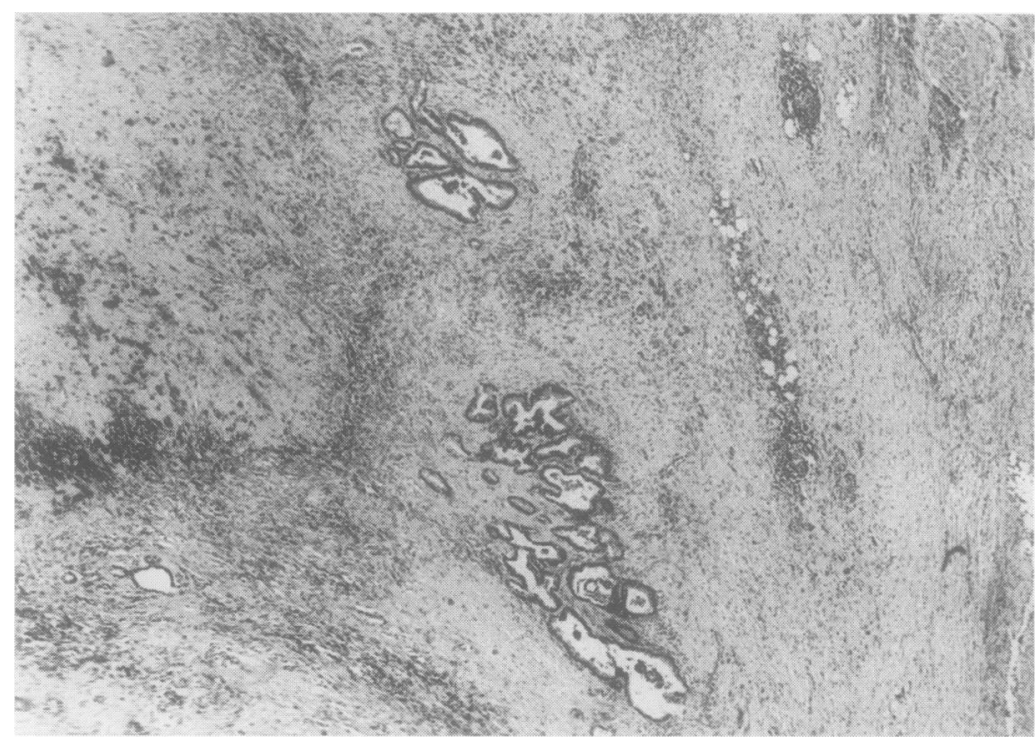

Figure 3 Although this mediastinal metastasis of a pulmonary adenocarcinoma was completely excised, the relation of the tumour to the nodal capsule is blurred by the extensive fibrosis. Tumour extension can best be classified as "indefinite".
The second part of the present study started with the definition of criteria for intranodal and extranodal growth, as these have been poorly defined. In metastasised breast cancer where extranodal tumour extension is accepted as integral part of TNM staging, extranodal disease is regarded as being present when there are demonstrable tumour cells outside the confines of the lymph node capsule after capsular penetration or destruction by the tumour. ${ }^{14-16}$ Obviously, it is assumed that a metastasis is intranodal when signs of extranodal growth are absent. Although this definition appears clear at first sight, it actually fails to take into account what the consequences are for classification if only a part of a lymph node is present in the histological section (instead of a complete node). Moreover, it does not clarify how vascular or lymphatic permeation should be regarded, and how the presence of tumour infiltration in hilar (efferent) lymphatic vessels should be judged. In the present study there was often no complete lymph node available for evaluation. If this was thought to be due to tissue processing in the Department of Pathologyfor example, a straight cut edge (fig 2) to the missing part of the lymph node, or when there was the impression that the tissue was not cut deeply enough-it was assumed that the growth pattern in the missing part was no different from that in the other part. Consequently, if no signs of extranodal growth were present, metastases were classified (at the second examination) as intranodal and not as indefinite. When tumour cells were found in the lumen of either an extranodal or a hilar (efferent) lymph vessel, this was regarded as being not truely extranodal, but intranodal, as these tumour cells were still situated within the lymphatic system. In the EORTC trial referred to earlier lymphatic permeation was regarded as extranodal tumour growth. Nevertheless, cases with tumour cells in efferent lymphatics could represent a special group, because this has prognostic implications in patients with breast cancer. ${ }^{17}$ The presence of tumour cells in the lumen of an extranodal vessel that was unequivocally a vein led to classification as extranodal tumour extension for pragmatic reasons: venous invasion is probably an important sign associated with haematogenous metastases and thus has prognostic implications as has been shown in many tumours including colonic and oesophageal carcinomas. ${ }^{18}{ }^{19}$ As the presence of only a few smooth muscle cells in the vessel wall does not discriminate between blood vessels and lymphatics, ${ }^{20}$ a vessel was only considered to be a vein when there was a clear circular layer of smooth muscle cells present in the vessel wall. In some cases artificial smearing of tumour cells into the lumen of a venous vessel caused interobserver variation. Sometimes a nerve was surrounded by tumour tissue, but this had to be regarded as proof of extranodal tumour growth, as there are no nerves within a lymph node.

If there was more than one transsection of a 
lymph node metastasis in a histological section, the metastasis was categorised as extranodal or indefinite when at least one transsection of the node showed such a change, even though the metastasis in the other transsections remained within nodal confines. Not all the situations that can be encountered in histopathological examination of lymph node metastases can be covered by criteria. In metastases with extensive desmoplastic stromal reaction it is often very difficult to identify the lymph node capsule due to fibrosis (fig 3). Consequently, such cases are an important cause of interobserver disagreement.

Another point of discussion is the shift in frequency distribution in classification categories at the second examination (table 1). A probable explanation for the shift from indefinite to intranodal in dissected lymph nodes is that the category of intranodal tumour extension was extended by the definition of the criteria. A possible explanation for the shift from indefinite to extranodal in the mediastinoscopic biopsy specimens is that the pathologists were more focused on extranodal growth patterns after the discussion on criteria.

Finally, some general recommendations to pathologists for standardised tissue processing seem important for improving the validity of the classification of tumour extension in mediastinal lymph node metastases: if possible, lymph nodes attached to one another should be separated carefully. Each lymph node should be cut completely into slices and completely processed for histological examination. Tissue blocks should be cut at various levels.

The results of the present study show that good interobserver agreement between pathologists on the classification of intranodal and extranodal tumour extension of $\mathrm{N} 2$ lymph node metastases in lung cancer can be achieved, provided that clear criteria have been defined beforehand. Despite these criteria, there is still a grey area between intranodal and extranodal tumour growth. The results of this study show that this is a substantial problem in mediastinal lymph node biopsy specimens. For these cases, a category of indefinite tumour extension should be used. Pathologists have to realise that nowadays these diagnostic categories have widely accepted therapeutic consequences. The clinical (prognostic) importance of nodal growth patterns in N2 metastasised NSCLC as defined in the present study has been confirmed in a separate study (unpublished observations).

We thank Professor S S Wagenaar, Department of Pathology, University Hospital Maastricht, for the critical review of the manuscript.

1 DeMeester TR. The staging issue: unification of criteria In: Delarue NC, Eschapasse $\mathrm{H}$, eds. International trends in general thoracic surgery. Vol 1. Philadelphia: WB Saunders, 1985:37-41.

2 Pearson FG, DeLarue NC, Ilves R, Todd TRJ, Cooper JD. Significance of positive superior mediastinal nodes identified at mediastinoscopy in patients with resectable cancer of the lung. $¥$ Thorac Cardiovasc Sury 1982;83: cancer

3 Ginsberg RJ, Kris MG, Armstrong JG. Lung cancer. In: De Vita VTjr, Hellman S, Rosenberg SA, eds. Cancer. Principles and practice of oncology. Philadelphia: JB Lippincott, 1993:673-758.

4 Meister $R$. Maligne lungentumoren. In: Gall FP, Hermanek P, Tonak J, eds. Chirurgische oncologie. Histologie-und stadiengerechte therapie maligner tumoren. Berlin: Springer, 1986:245-91.

5 Shields TW. The significance of ipsilateral mediastinal lymph node metastasis (N2 disease) in non-small cell lymph node metastasis (N2 disease) in non-small cell carcinoma

6 Thermann M, Bluemm R, Schroeder U, Wassmuth E, Dohmann R. Efficacy and benefit of mediastinal computed tomography as a selection method for mediastinoscopy. Ann Thorac Surg 1989;48:565-7.

7 Bergh NP, Schersten T. Bronchogenic carcinoma. A follow up study of surgically treated series with special reference to the prognostic significance of lymph node metastasis. Acta Chir Scand 1965;Suppl 347:1-42.

8 Larsson S. Pretreatment classification and staging of bronchogenic carcinoma. Scand $\mathcal{f}$ Thorac Cardiovasc bronchogenic carcinoma.

9 Ishida T, Tateishi M, Kaneko S, Sugimachi S. Surgical treatment of patients with non small-cell lung cancer and mediastinal lymph node involvement. $\mathcal{f}$ Surg Oncol 1990;43:161-6.

10 Naruke T, Suemasu K, Ishikawa S. Lymph node mapping and curability at various levels of metastasis in resected lung cancer. $\mathcal{F}$ Thorac Cardiovasc Surg 1978;76:832-9.

11 Cohen J. A coefficient of agreement for nominal scales. Educ Psychol Measurement 1960;20:37-46.

12 Schouten HJA. Nominal scale agreement among observers. Psychometrika 1986;51:453-66.

13 Landis RJ, Koch GG. The measurement of observer agreement for categorial data. Biometrics 1977;33: agreement

14 Mambo NC, Gallager HS. Carcinoma of the breast. The significance of extranodal extension of axillary disease. Cancer 1977;39:2280-5.

15 Fisher ER, Gregorio RM, Redmond C, Kim WS, Fisher B. Pathologic findings from the national surgical adjuvant breast project. The significance of extranodal extension of axillary metastases. Am $\mathcal{F}$ Clin Pathol 1976;65: 439-44.

16 Donegan WL, Stine SB, Samter TG. Implications of extracapsular nodal metastases for treatment and prognosis of breast cancer. Cancer 1993;72:778-2.

17 Hartveit F, Skjaerven R, Maehle O. Prognosis in breast cancer patients with tumour cells in the efferent vessels
of their axillary nodes. $\mathcal{F}$ Pathol $1982 ; 139: 379-82$.

18 Talbot IC, Ritchie S, Leighton MH, Hughes AO, Bussey HJR, Morson BC. Spread of rectal cancer within veins. Histologic features and clinical significance. Am $\mathcal{F}$ Surg 1981;141:15-17.

19 Theunissen PHMH, Borchard F, Poortvliet DCJ. Histopathological evaluation of oesophageal carcinoma: the significance of venous invasion. Br 7 Surg 1991;78. 930-2.

20 The circulatory system. In: Cormack DH, ed. Ham's histology. 9th edn. Philadelphia: JB Lippincott, 1987: 423-49. 